\title{
O DESCARTE, O RECOLHIMENTO E A DESTINAÇÃO DE MEDICAMENTOS VENCIDOS E A VENCER PELA POPULAÇÃO NO MUNICÍPIO DE PRESIDENTE PRUDENTE: BREVES COMENTÁRIOS À LEI MUNICIPAL N. 7012/2009.
}

\author{
Renata Cristina Mafra, Fábio Ferreira Morong \\ Universidade do Oeste Paulista-UNOESTE, Faculdade de Direito de Presidente Prudente, Presidente \\ Prudente, SP, e-mail: renatacmafra@hotmail.com
}

\begin{abstract}
RESUMO
O descarte de medicamentos vencidos pela população brasileira é uma questão de ordem ambiental e sanitária, eis que a destinação final inadequada desses resíduos pode causar impactos relevantes. Apesar de não existir uma Lei Federal regulamentadora sobre esse assunto, as normas técnicas e legislações estaduais e municipais, ainda que de forma desordenada, regulam substancialmente alguns critérios de logística reversa. Este trabalho pretende analisar a Lei Municipal n. 7012/2009, que disciplina o descarte, o recolhimento e a destinação de medicamentos vencidos e a vencer pela população de Presidente Prudente, demonstrando suas características mais relevantes. O método utilizado foi o dedutivo legal, aplicando-se a interpretação de legislação e doutrina. Conclui-se que é imprescindível a elaboração urgente de um decreto regulamentador com objetivo de ensejar total eficácia à Lei Municipal já existente, sem prejuízo de ações específicas no sentido de aperfeiçoar a citada Lei Municipal, como fator preponderante à proteção ambiental e a saúde pública de modo geral.

Palavras-chave: descarte de medicamentos vencidos, Lei Municipal 7012/2009, logística reversa, Decreto, impacto ambiental e sanitário.

\section{MAJOREFFECTS OF THE CONDUCT ADJUSTMENT AGREEMENT IN ENVIRONMENTAL MATTERS INCIVIL AND ADMINISTRATIVE FIELD}

\begin{abstract}
Dispose of expired medications by the brazilian population is a matter of environmental and health order, behold the inadequate final disposal of such waste may cause relevant impacts. Although there is no federal regulatory law, technical standards and municipal and state legislation, albeit in disorderly way, substantially adjust some criteria of reverse logistics.

This work intends to analyze the municipal law No. 7012/2009, that discipline the disposal, the collection and disposal of expired medicines and the win by the population of Presidente Prudente, demonstrating their most relevant characteristics. The method used was the legally deductive, applying the interpretation of legislation and doctrine. It is concluded that it is essential the development of a regulatory decree to justify full effectiveness to existing municipal law, without prejudice to specific actions in order to improve the municipal law, as a predominant factor to environmental protection and public health in general.

Keywords: Conduct Adjustment Agreement (TAC), environment, transaction, sphere civil, sphere administrative.
\end{abstract}




\section{INTRODUÇÃO}

O Brasil é o sétimo país do mundo em venda de medicamentos, com cerca de 70,4 mil farmácias (BURLE, 2016). Mesmo diante disso, não existe no país uma Lei específica que regulamente o descarte de remédios vencidos ou sem uso pelo consumidor doméstico. De outro lado, o Poder Público competente ainda não logrou êxito em alcançar uma solução juntamente com empresas do setor para adotar os pressupostos de uma logística reversa eficaz. Assim, o país convive diariamente com os potenciais riscos ambientais e de saúde pública decorrentes do referido problema.

É certo que não existe uma norma nacional que regulamente o descarte de medicamentos vencidos, de modo que alguns Estados e Municípios estabeleceram regulamentos próprios em relação à logística reversa prevista originalmente pela Lei de Resíduos Sólidos.

Nesse contexto, busca-se com o presente trabalho analisar a Lei Municipal n. 7012/2009, que disciplina o descarte, o recolhimento e a destinação de medicamentos vencidos e a vencer pela população no município de Presidente Prudente, demonstrando suas características e objetivos mais relevantes e apontando a ausência de decreto regulamentador que contribui diretamente de forma negativa para o alcance da plena eficácia da referida lei.

\section{DOS MEDICAMENTOS VENCIDOS COMO RESÍDUOS DE SERVIÇOS DE SAÚDE (RSS) E A POLÍTICA NACIONAL DE RESÍDUOS SÓLIDOS}

Sabe-se que os resíduos sólidos provenientes da atividade farmacêutica são considerados Resíduos de Serviços de Saúde (RSS), segundo a classificação utilizada pela RDC ANVISA no 306/04, que divide a geração de resíduos em cinco grupos. Para Ferreira (2000), os resíduos hospitalares (ou de serviços de saúde) são os resíduos produzidos pelas atividades de unidades de serviços de saúde (hospitais, ambulatórios, postos de saúde etc.).

A mencionada norma da ANVISA (306/2004) também passou a tratar do Regulamento Técnico para o gerenciamento de resíduos de serviços de saúde, prevendo o um Plano de Gerenciamento de Resíduos de Serviços de Saúde (PGRSS), que consiste em um documento que aponta e descreve as ações relativas ao manejo dos resíduos sólidos, observadas suas características e riscos, no âmbito dos estabelecimentos, contemplando os aspectos referentes à geração, segregação, acondicionamento, coleta, armazenamento, transporte, tratamento e disposição final, bem como as ações de proteção à saúde pública e ao meio que descreve as ações a serem elaboradas no manejo (BECHARA, 2013). Vê-se que a resolução foi uma das principais ferramentas empregadas para ponderação e orientação quanto ao gerenciamento dos resíduos das farmácias desde sua formação até seu descarte final, implicando na atribuição das responsabilidades do estabelecimento gerador e definindo normas para elaboração do plano de ação para a vigilância local (GONÇALVES et al., 2008, p. 338).

Já no ano de 2010, foi promulgada a Lei Federal n.o 12.305/10, que instituiu a Política Nacional de Resíduos Sólidos, estabelecendo os princípios, objetivos, instrumentos, diretrizes, metas e ações a serem adotados, através dos planos de resíduos sólidos. (JÚNIOR; SAIANI; DOURADO, 2014, p.103). A citada lei melhorou alguns aspectos e definições importantes antes conhecidos pela resolução ANVISA 306/2004, de maneira que diante da nova perspectiva nacional acerca do gerenciamento de resíduos sólidos, o manejo dos Resíduos de Serviços de Saúde obteve uma maior importância, haja vista a necessidade de manutenção da qualidade de vida e a manutenção do meio ambiente. Assim, foram ratificados e desenvolvidos os termos do Plano de Gerenciamento de Resíduos de Serviços de Saúde (PGRSS), apesar de não haver nenhuma menção específica pela citada lei federal no que tange ao descarte de medicamentos.

Importante salientar que, além da citada lei, aplicam-se de forma geral aos resíduos sólidos as Leis n.o 11.445/2007, 9.974/2000, e 9.966/2000, ademais das normas estabelecidas pelos órgãos do Sistema Nacional do Meio Ambiente (Sisnama), do Sistema Nacional de Vigilância 
Sanitária (SNVS), do Sistema Unificado de Atenção à Sanidade Agropecuária (Suasa) e do Sistema Nacional de Metrologia, Normalização e Qualidade Industrial (Sinmetro), nelas contendo a Resolução da Diretoria Colegiada - RDC n. 306/04 como a Resolução CONAMA n. 358/05, quando se tratar de Resíduos de Serviços de Saúde (RSS). (BALBINO, E.; BALBINO, M.; 2011)

Como se pode observar tanto a Resolução da Diretoria Colegiada - RDC n. 0 306/04 como a Resolução CONAMA n.o 358/05 e a Lei n.o 12.305/10, entre outras normas esparsas, estabelecem critérios para o gerenciamento de resíduos sólidos, porém, não em âmbito específico, inexistindo normatização especial em relação à execução de gerenciamento dos referidos resíduos, ou seja, o descarte de medicamentos vencidos.

\section{DA AUSENCIA DE NLEI FEDERAL ESPECÍFICA E AS NORMAS ESPARSAS SOBRE O TEMA}

De acordo com Burle (2016, p. 01), "apesar de grande consumidor de medicamentos, o Brasil não tem lei nem norma específica sobre o descarte dos produtos vencidos, que podem trazer riscos para o meio ambiente e a saúde pública". Denota-se que como grande parte dos medicamentos não utilizados é descartada ao meio de maneira inadequada, a ausência de um sistema de logística reversa acaba elevando o risco de contaminação. Por sua vez, com a evolução trazida pela Lei 12.305, a logística reversa tem como escopo que a manufatura regresse ao seu fabricante, em decorrência dos impactos ambientais. Por isso, os fabricantes dos seguintes produtos estão obrigados a coletar e dar destinação correta para: pilhas, baterias, pneus, lubrificantes, eletroeletrônicos e determinadas espécies de lâmpadas. (JARDIM; YOSHIDA; MACHADO FILHO, 2012, p.338). Entretanto, apesar do artigo 17 do Decreto 7.404/2010 que regulamenta da Lei 12.305 , não compreender todos os resíduos supramencionados, não há óbice para que a logística reversa se amplie a um rol mais extenso de resíduos e não fique limitado aos acima referidos (WINDHAN-BELLORD; SOUZA, 2011).

Nesse contexto, Servinskas (2010, p. 455) salienta que antes mesmo da publicação da lei federal alguns Estados brasileiros já haviam adiantado o tema, positivando em suas legislações, dentre os quais o Estado de São Paulo que em 2006 publicou a Lei estadual n. 12.300, que instituiu a Política Estadual de Resíduos Sólidos, e já no ano seguinte pode colher resultados positivos. Não é diferente em outros Estados, a exemplo do Paraná, que implementou a lei 17.211 de 2012, que dispõe sobre a responsabilidade da destinação dos medicamentos em desuso no estado e seus procedimentos, prevendo a cobrança de multa para aqueles que não se adequarem à lei. (Paraná, 2012), bem como do Estado do Amazonas, por meio da Lei 3676/2011, que cuidou da distribuição de competências e de multas. De igual forma o Estado do Ceará, por meio da lei n. 15.192/2012, que definiu as normas para o descarte de medicamentos vencidos ou fora de uso. (MEDEIROS; MOREIRA; LOPES, 2014, p.657).

Em âmbito municipal, vários municípios já têm legislação específica sobre o assunto. Pode-se citar como exemplo, o município de Cuiabá, que por meio da Lei 5.678/13, prevê a coleta de medicamentos vencidos ou não utilizados em farmácias revendedoras, de manipulação e drogarias. Igualmente o município de Passo Fundo (RS), que instituiu a Lei 4.462/07, que dispõe sobre a obrigatoriedade de as farmácias manterem urnas para a coleta de medicamentos, insumos farmacêuticos, correlatos, cosméticos deteriorados ou com prazo de validade expirado. Na mesma esteira vem a cidade de Porto Alegre, que instituiu a Lei 11.329/12 regulamentando o descarte e vinculando as farmácias a receberem e acondicionarem os medicamentos e suas embalagens, bem como providenciar o destino ambientalmente adequado. (MOROSINI, 2015, p. 27).

Importante ressaltar que na Câmara dos Deputados, tramita um projeto de lei sob o $\mathrm{n}$. 7.064, de 2014, que foi apensado a outro pré-existente sob o n. 2121/2011. O projeto de lei de 2011 determina as drogarias e farmácias, entre elas as de manipulação, a manter recipiente em local de fácil visualização, para recolhimento de medicamentos impróprios para o consumo ou com data de validade vencida. O PL 2.121 de 2011 prevê também que esses estabelecimentos 
devem informar aos consumidores sobre os riscos de descarte de medicamento de modo inapropriado (Brasil, 2011). Já projeto de lei sob o n. 7.064 de 2014 apresenta as razões para a implantação da logística reversa de medicamentos e destaca a tentativa da Agência Nacional de Vigilância Sanitária em criar uma acordo setorial que contemple a logística reversa de medicamentos em substituição a uma política pública que considere o tema. Aborda ainda, a importância da educação ambiental para a mudança de mentalidade sobre o assunto (Brasil, 2014).

Atualmente, está tramitando junto á Câmara dos Deputados, tramita o mais recente projeto de lei sob o n. 5152/2016, que também foi apensado ao PL 2121/2011. O recente projeto de lei tem como objetivo principal dividir o ônus de dar destino final aos medicamentos vencidos e outros produtos, mediante a responsabilização dos respectivos fabricantes e distribuidores -, ao mesmo tempo que institui uma solução com menores riscos ao meio ambiente, uma vez que as indústrias, necessariamente terão melhores condições e meios do que os comerciantes para fazer um descarte seguro daqueles resíduos (Brasil, 2016). Pois bem, denota-se que realmente inexiste uma só norma legal federal tratando do que fazer com medicamentos vencidos ou deteriorados, como se a ocorrência de tais situações não fosse previsível. No entanto, não há dúvidas de que as normas técnicas, legislações estaduais e municipais existentes de forma esparsa contribuem, ainda que de forma desordenada, à formação de uma conscientização do poder público no sentido de começar a preocupar-se com o problema do descarte de medicamentos vencidos pela população. Neste contexto, está inserido o Município de Presidente Prudente/SP, que no ano de 2009 promulgou a Lei Municipal n. 7012/2009, que disciplina o descarte, o recolhimento e a destinação de medicamentos vencidos e a vencer pela população no município de Presidente Prudente, como veremos a seguir.

\section{DA LEI MUNICIPAL N. 7012/2009: CARACTERÍTICAS GERAIS}

A Lei Municipal n. 7012/2009, em seu artigo primeiro, determina que o usuário deve depositar todo tipo medicamento comercializado no Município de Presidente Prudente em recipientes previamente instalados nas farmácias e nos postos de saúde e remetidos à Vigilância Sanitária. No mesmo dispositivo legal, denota-se que os medicamentos vencidos deverão ser remetidos à Vigilância Sanitária para que possam ser repassados aos fabricantes, aos distribuidores ou aos importadores, para que estes adotem os procedimentos de destinação final ambientalmente adequada.

Pois bem, de proêmio observa-se que a lei municipal impõe duas obrigações. A primeira a todo o usuário (qual seja, depositar todo tipo medicamento comercializado em recipientes) e a segunda aos fabricantes, aos distribuidores ou aos importadores, que serão os responsáveis pela destinação final ambientalmente adequada. Já no seu artigo 2으, a legislação municipal impõe o dever aos estabelecimentos que comercializam medicamentos de disponibilizar ao público em geral caixas de coleta de fármacos vencidos no seu interior para, posteriormente remetê-los ao órgão sanitário do Município. Percebe-se que não existe no comando legal a descrição das características técnicas e específicas dos mencionados recipientes para coleta do material vencido, inexistindo um padrão técnico e ambiental que poderia ser adotado com critérios mais claros, propiciando um melhor controle sanitário e ambiental.

Por sua vez, a lei municipal também prevê em seu artigo 3ํ, como medida transitória, isto é, não definitiva, a possibilidade de criação de entrepostos alternativos pelo Município, para recebimento dos medicamentos a serem descartados pelos usuários. Estabelece o mesmo artigo que tais entrepostos somente estarão em operação até que sejam estruturados mecanismos operacionais para a coleta, transporte e armazenamento dos medicamentos vencidos, de modo que tal medida está voltada à prevenção ambiental e cuidados com a saúde pública local. 
Nota-se nesta vertente que uma vez mais a legislação foi omissa no sentido de esclarecer os critérios técnicos eventualmente estabelecidos para a instituição dos tais entrepostos alternativos. Tampouco vislumbrou de quem é a responsabilidade pela criação dos mecanismos operacionais para a coleta, transporte e armazenamento desses produtos, o que descaracteriza o caráter transitório do objetivo do citado dispositivo, afetando a eficácia da lei municipal em estudo.

A informação à população é muito bem privilegiada pelo artigo 4음 la lei aqui analisada. 0 legislador municipal foi feliz ao estabelecer que a população tenha o direito a receber todas as informações inerentes à importância e necessidade do usuário se desfazer do medicamento com data de validade vencida e a vencer, como forma de prevenção a danos ao meio ambiente e a saúde pública. Merece destaque esta posição legal, pois a informação direta à população contribui não só para o aspecto preventivo como também ao desenvolvimento da conscientização social acerca deste problema que pode prejudicar não só o meio ambiente como também à saúde local e regional.

Pois bem, todas essas obscuridades da lei municipais poderão ser esclarecidas com o cumprimento do seu próprio artigo 5으, que trata de instituição de um Decreto municipal que possibilite a regulamentação da lei em comento. $O$ dito artigo prevê a criação de um decreto que possibilite sua regulamentação, porém, desde 2009, nenhuma medida ou iniciativa legislativa foi efetivada. Neste contexto, é certo que uma lei não regulamentada, apesar de que a regulamentação esteja nela prevista, é totalmente ineficaz, ou seja, qualquer ato nela baseado pode incorrer em inconstitucionalidade, uma vez que são feridos dois princípios constitucionais, qual seja, o descrito no art. $5^{\circ}$, inciso LIV, da Constituição Federal que prescreve que "ninguém será obrigado a fazer ou deixar de fazer alguma coisa senão em virtude de lei, válida e eficaz'; e o de que 'ninguém será privado da liberdade ou de seus bens sem o devido processo legal.

A fim de tentar resolver essa questão seria imprescindível apontar as formas para sua efetivação, ou seja, definir prazos, sanções e exceções, com o escopo de evitar a necessidade de regulamentação obrigatória pelo Executivo, possibilitando a imediata aplicação da lei.

\section{CONCLUSÃO}

O problema relacionado ao descarte de medicamentos vencidos pela população brasileira é uma questão de ordem ambiental e sanitária, eis que a destinação final inadequada desses resíduos pode causar impactos relevantes. Apesar de não existir uma Lei Federal regulamentadora sobre esse assunto, as normas técnicas e legislações estaduais e municipais, ainda que de forma desordenada, regulam substancialmente alguns critérios de logística reversa. O presente trabalho buscou analisar a Lei Municipal n. 7012/2009, que disciplina o descarte, o recolhimento e a destinação de medicamentos vencidos e a vencer pela população no município de Presidente Prudente, demonstrando suas características e objetivos mais relevantes e apontando a ausência de decreto regulamentador que contribui diretamente de forma negativa para o alcance da plena eficácia da referida lei. O estudo conclui que, em que pese a iniciativa positiva do legislador municipal, é imprescindível a elaboração urgente de um decreto regulamentador com objetivo de ensejar total eficácia à Lei Municipal já existente, sem prejuízo de ações por parte do poder público e da iniciativa privada no sentido de aperfeiçoar a citada Lei Municipal, como fator preponderante à proteção ambiental e a saúde pública de modo geral.

\section{REFERÊNCIAS}

BALBINO, E.; BALBINO, M. O descarte de medicamentos no Brasil: Um olhar socioeconômico e ambiental do lixo farmacêutico. Revista Âmbito Jurídico. Março/2011. Disponível em: $<$ http://www.ambito- 
juridico.com.br/site/index.php?artigo_id=9187\&n_link=revista_artigos_leitura>. Acesso em: 01 Ago. 2016.

BECHARA, E. Aspectos relevantes da política nacional de resíduos sólidos Lei $n^{\circ} 12.305 / 2010$. Atlas, 2013. em: <https://integrada.minhabiblioteca.com.br/\#/books/9788522477548/cfi/3!/4/4@0.00:59.5>. Acesso em: 03 ago. 2016.

Brasil. Câmara dos Deputados. Projeto de lei 2121 de 2011. Dispõe sobre o descarte de medicamentos vencidos ou impróprios para o consumo nas farmácias e drogarias e dá Outras providências. 2011. Disponível em <http://www.camara.gov.br/proposicoesWeb/fichadetramitacao?idProposicao $=517210>$. Acesso em 01 ago 2016.

Brasil. Câmara dos Deputados. Projeto de lei 7064 de 2016. Dispõe sobre o recolhimento de medicamentos vencidos e a devolução de medicamentos excedentes ainda em validade, e dá outras $\quad$ providências. $2014 \quad$ Disponível em $<$ http://www.camara.gov.br/proposicoesWeb/fichadetramitacao?idProposicao $=517210>$. Acesso em 01 ago 2016.

BURLE, S. O perigo do remédio sem uso na farmacinha de cada casa. Agência Senado, Brasília, 12 abril 2016. Disponível em: <http://www12.senado.leg.br/noticias/materias/2016/04/12/o-perigodo-remedio-sem-uso-na-farmacinha-de-cada-casa>. Acesso em: 15 abril 2016.

FERREIRA, J. Resíduos Sólidos: Perspectivas Atuais. In: SISNINO, Cristina Lúcia Silveira \& OLIVEIRA, Rosália Maria de. (orgs.). Resíduos Sólidos, Ambiente e Saúde: uma visão multidisciplinar. 3 Reimpressão. Rio de Janeiro. Editora Fiocruz; 2000. 142p.

GOLÇALVES, C \& et al. Gerenciamento de Resíduos de uma farmácia magistral situada em Vila Velha, ES: um estudo de caso. Revista Brasileira de Farmácia. Rio de Janeiro, p. 337-341. 2008. Disponível em: <http://www.rbfarma.org.br/files/pag_337a341_gerenciamento_residuos.pdf>. Acesso em 30 jul. 2016.

JARDIM, A.; YOSHIDA, C.; MACHADO FILHO, J. (eds). Política Nacional. Gestão e Gerenciamento de Resíduos Sólidos. São Paulo: Manole, 2012. Disponível em: <https://integrada.minhabiblioteca.com.br/\#/books/9788520444801/first>. Acesso em: 03 ago. 2016.

JÚNIOR, R.; SAIANI, S.; DOURADO, J. (orgs). Resíduos Sólidos no Brasil: Oportunidades e Desafios da Lei Federal n. 12305 (Lei de Resíduos Sólidos). São Paulo: Manole, 2014. Disponível em: <https://integrada.minhabiblioteca.com.br/\#/books/9788520449240/cfi/0!/4/2@100:0.00>. Acesso em: 03 ago. 2016.

MEDEIROS, M.; MOREIRA, L.; LOPES, C. Descarte de medicamentos: programas de recolhimento e novos desafios. Revista de Ciências Farmacêuticas Básica e Aplicada. Araraquara, p. 651-662, 2014.

MOROSINI, L.; Descarte é responsabilidade de quem? Revista Radis Fio Cruz. Rio de Janeiro, $\mathrm{n}$. 154, p. 27-29, jul. 2015. 
Primeira norma nacional de logística reversa de medicamentos descartados pelo consumidor entra em consulta pública. ABES - Associação Brasileira de Engenharia Sanitária e Ambiental. Rio de Janeiro. Disponível em: <http://abes-dn.org.br/?p=571\#>. Acesso em: 03 ago. 2016.

WINDHAN, K.; SOUZA, P.; O caminho de volta: Responsabilidade compartilhada e logística reversa. Revista Ambiental v. 63. São Paulo: Revista dos Tribunais, 2011. 